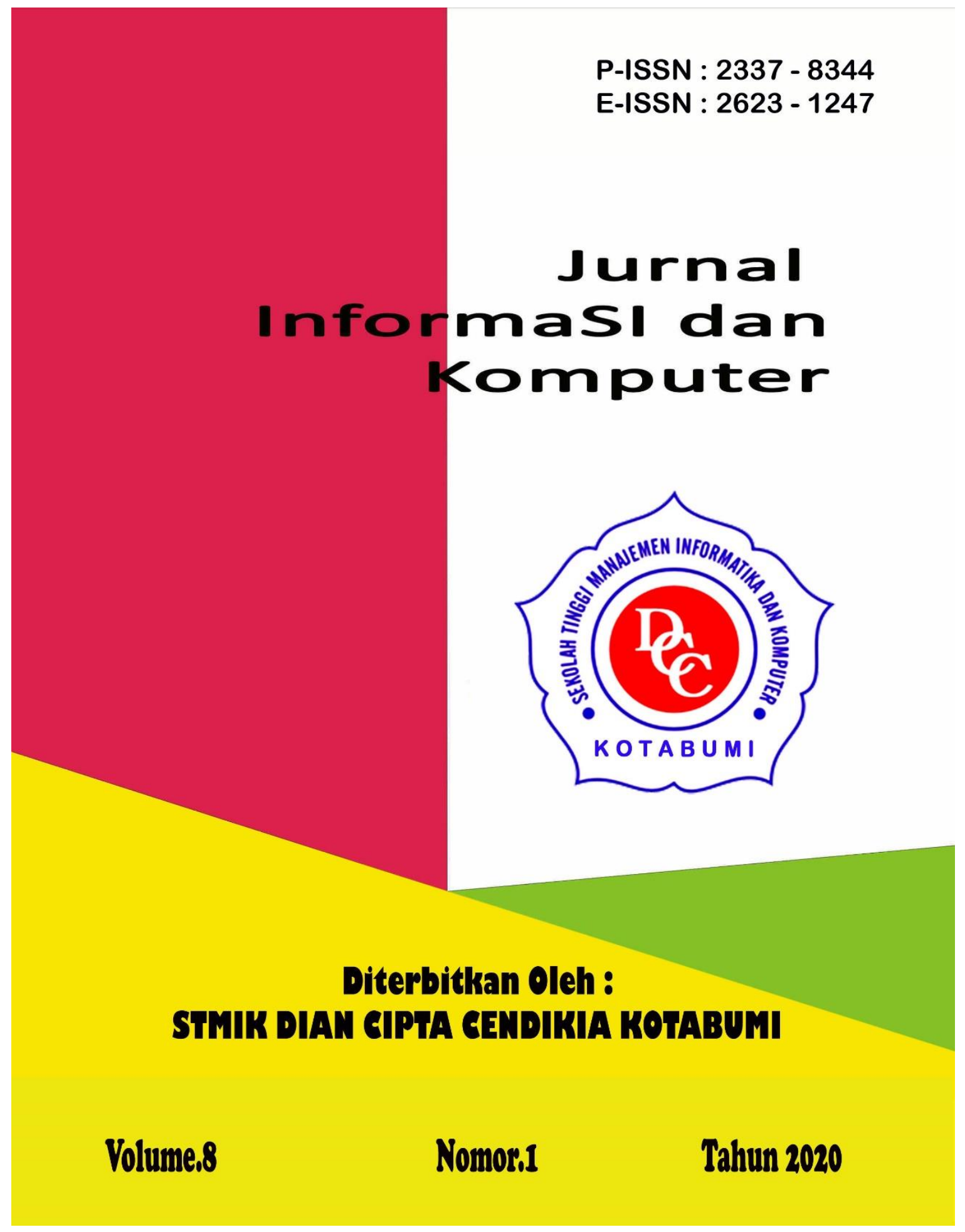




\section{Penerbit:}

STMIK DIAN CIPTA CENDIKIA KOTABUMI

Bekerjasama dengan LPPM STMIK DCC Kotabumi

Hak atas naskah/tulisan tetap berada pada penulis, isi diluar tanggung jawab Penerbit dan Dewan Penyunting

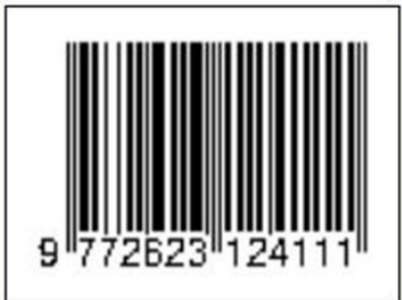




\section{PENGANTAR REDAKSI}

Puji syukur dipanjatkan kehadirat Tuhan Yang Maha Esa, atas karunia dan limpahan rahmatNYA jualah Jurnal Informatika dan komputer (InfoKom) STMIK Dian Cipta Cendikia Kotabumi ini dapat terwujud.Jurnal Informatika dan Komputer (InfoKom) yang terbit dua (2) kali dalam setahun ini merupakan suatu wadah untuk penyebar luasan hasil-hasil penelitian, studi pustaka, karya ilmiah yangberkaitan dengan Informatika dan Komputer khususnya bagi dosen-dosen STMIK Dian Cipta Cendikia Kotabumi serta umumnya para cendikiawan, praktisi, peneliti ilmu Informatika dan Komputer.

Harapan, dengan diterbitkannya Jurnal Informatika dan Komputer (InfoKom) ini sebagai salah satu bentuk sumbangan pemikiran dalam pengembangan ilmu informatika dan komputer yang berkaitan dengan kajian-kajian di bidang tekhnologi Informatik, Komunikasi Data dan Jaringan Komputer, perancangan dan Rekayasa Perangkat Lunak, serta ilmu-ilmu yang terkait dengan bidang Informatika dan Komputer lainnya.

Berkenaan dengan harapan tersebut, kepada para peneliti, dosen dan praktisi yang memiliki hasil-hasil penelitian, kajian pustaka, karya ilmiah dalam bidang tersebut diatas, dengan bangga redaksi Jurnal Informatika dan Komputer (JIK) menerima naskah ringkasan untuk dimuat pada jurnal Informatika dan Komputer (InfoKom) STMIK Dian Cipta Cendikia Kotabumi dengan berpedoman pada penulisan naskah jurnal sebagaimana dilampirkan pada halaman belakang (Bagian kulit dalam) buku jurnal ini.

Mutu dari suatu jurnal ilmiah tidak hanya ditentukan oleh para pengelolanya saja, tetapi para penulis dan pembaca jualah yang mempunyai peranan besar dalam meningkatkan mutu jurnal Informatika dan Komputer ini. Merujuk pada realita ini kamu sangat mengharapkan peran aktif dari peneliti untuk bersama-sama menjaga dan memelihara keberlangsungan dari jurnal Informatika dan Komputer STMIK Dian Cipta Cendikia Kotabumi ini. Yang juga tidak kalah pentingnya dari partisipasi tersebut diatas, adalah saran dan kritik yang membangun dari pembaca yang budiman agar kiranya dapat disampaikan langsung kepada redaksi JIK. Saran dan kritik yang membangun akan dijadikan masukan dan pertimbangan yang sangat berarti guna peningkatan mutu dan kualitas Jurnal Informatika dan Komputer STMIK Dian Cipta Cendikia Kotabumi.

Tak lupa diucapkan terima kasih yang tak terhingga atas perhatian dan kerjasama dari semua pihak yang tak dapat disebutkan satu persatu hingga dapat diterbitkan nya Jurnal Informatika dan Komputer (InfoKom) STMIK Dian Cipta Cendikia Kotabumi. Semoga apa yang telah diperbuat untuk kebaikan akan menjadi amal ibadah, amin.

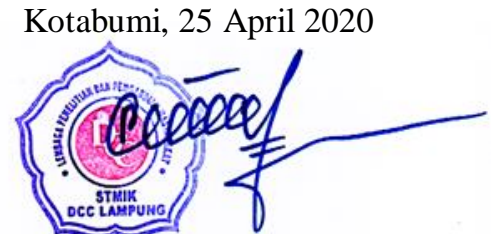

Dewan Redaksi 


\section{JURNAL INFORMASI DAN KOMPUTER Volume 8 Nomor 1 April 2020}

Jurnal Informasi dan Komputer merupakan Sarana informasi ilmu pengetahuan, Tekhnologi dan Komunikasi yang berupa hasil penelitian, tulisan ilmiah, Ataupun studi pustaka. Jurnal ini terbit dua kali setahun pada bulan April dan Oktober. Berisi hasil penelitian ilmiah di bidang informatika yang bertujuan untuk menghubungkan adanya kesenjangan antar kemajuan teknologi dan hasil penelitian. Jurnal ini di terbitkan pertama kali pada tahun 2013.

Penanggung Jawab:

Ketua STMIK Dian Cipta Cendikia

Kotabumi

\section{Pembina:}

Ketua STMIK Dian Cipta Cendikia

Kotabumi

Ketua Lembaga Penelitian STMIK Dian

Cipta Cendikia Kotabumi

\section{Pimpinan Redaksi}

Dwi Marisa Efendi,.S.Kom.,M.Ti

\section{Redaksi pelaksana}

Rustam,.S.Kom,.M.Ti (STMIK Dian

Cipta Cendikia Kotabumi)

Nurmayanti M.Kom (STMIK Dian

Cipta Cendikia Kotabumi)

Sukatmi,.S.Kom., M.Kom (AMIK DCC

Bandar Lampung)

Sampurna Dadi Riskiono,M.Kom

(Universitas Teknokrat Indonesia)

Ifo Wahyu

Pratama,S.Kom.,M.Ti(AMIK MASTER

Lampung)

\author{
Mitra Bestari \\ Merri Parida.,M.Kom (STMIK Dian \\ Cipta Cendikia Kotabumi) \\ Amarudin,S.Kom.,M.Eng (Universitas \\ Teknokrat Indonesia) \\ Didi Susianto.,S.T.,M.Kom (AMIK \\ DCC Bandar Lampung) \\ Alhibarsyah.,S.T.,M.Kom (Stmik Tunas \\ Bangsa Bandar Lampung) \\ Kemal Farouq Mauladi \\ .,S.Kom.,M.Kom (Universitas Islam \\ Lamongan) \\ Agus Setiawan S.Pd.,M.Eng \\ (Universitas Muhammadiyah \\ Lamongan)
}

Penerbit : STMIK Dian Cipta Cendikia Kotabumi Bekerja Sama Dengan LPPM STMIK Dian Cipta Cendikia Kotabumi.

\author{
Alamat Redaksi/Penerbit: \\ Jl. Negara No. 3 Candimas Kotabumi \\ Lampung Utara \\ No Telpon/Fax 072423003 \\ Email : 1ppm-stmik@dcc.ac.id
}




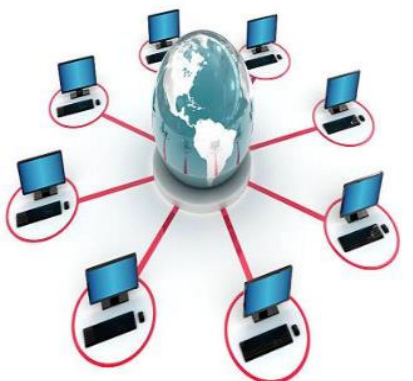 \\ JURNAL INFORMASI DAN KOMPUTER VOL. 8 NO. 1 THN. 2020}

\section{DAFTAR ISI}

\section{Halaman}

Sistem Pendukung Keputusan Penentuan Lahan Kopi Terbaik Dengan Metode

Ahp (Analytic Hierarchy Process)

Sidik Rahmatullah, Rendy Abdurahman (AMIKKOM Jogja,

STMIK Dian Cipta Cendikia Kotabumi)

Rancang Bangun Sistem Informasi Pada Program Pembangunan Pemberdayaan

Masyarakat Desa( P3md ) Berbasis Web Mobile

Ferly Ardhy, Firmansyah, Sidik Rahmatullah,(IIB Darma Jaya Bandar Lampung

STMIK Dian Cipta Cendikia Kotabumi, AMIKKOM Jogja)

Sistem Informasi Pengolahan Data Alumni Sekolah Menengah Atas (Sma)

Merri Parida, Nindiya Ova Rahmawati (AMIKKOM Jogja,

STMIK Dian Cipta Cendikia Kotabumi)

SISTEM INFORMASI GEOGRAFIS PUSKESMAS BESERTA SARANA

DAN PRASARANA BERBASIS WEB MOBILE

Nurmayanti, Windy Dwi Bahari (AMIKOM Jogja,

STMIK Dian Cipta Cendikia Kotabumi)

Rancang Bangun Sistem Informasi Konseling Untuk Sekolah Menengah Kejuruan

(Smk) Berbasis Website

Aliy Hafiz1, Galih Rakasiwi, Ifo Wahyu Pratama, Agus Komarudin,

Bambang Suparapto, Fathurrahman Kurniawan Ikhsan

(AMIK Dian Cipta Cendikia Bandar Lampung,

Universitas Nahdhatul Ulama Lampung, AMIK Dian Cipta Cendikia Pringsewu,

Universitas Mitra Indonesia, Lampung) .....

Sistem Pendukung Keputusan Pemilihan Driver Terbaik Menggunakan Metode

Weight Product (Wp)

Dina Lorenza, Pitrawati (STMIK Dian Cipta Cendikia Kotabumi

AMIK Dian Cipta Cendikia)

Rancang Bangun Sistem Informasi Pembayaran Mahasiswa

Darsin(Universitas Megou pak Tulang Bawang)

Sistem Informasi Geografis Bengkel Motor Honda Resmi Bandar Lampung

Sukatmi, Nuraini (AMIK Dian Cipta Cendikia Bandar Lampung).....

Sistem Pakar Diagnosa Penyakit Kulit Wajah Dengan Metode

Certainty Factor Pada Klinik Skin Rachel

Dwi Marisa Efendi, Putri Yulita Sari (IIB Darmajaya Bandar Lampung,

STMIK Dian Cipta Cendikia Kotabumi) 
Sistem Informasi Monitoring Siswa Pada Mts Al-Islamiah Bunut Kabupaten Pesawaran Yuli Syafitri ${ }^{2}$, Reni Astika ${ }^{1}$, Septian Hernando $^{3}$ AMIK Dian Cipta Cendikia

Aplikasi Kamus Bahasa Jepang Berbasis Mobile Android

Rustam $^{2}$, A Yanda Febry Pangestu ${ }^{2}$ Sistem Informasi, Teknologi Komputer ${ }^{1}$, IIB Darmajaya

Bandar Lampung ${ }^{2}$ STMIK Dian Cipta Cendikia Kotabumi 


\title{
SISTEM INFORMASI PENGOLAHAN DATA ALUMNI SEKOLAH MENENGAH ATAS (SMA)
}

\author{
Merri Parida ${ }^{1}$, Nindya Ova Rahmawati ${ }^{2}$ \\ SistemInformasi ${ }^{1}$, Sistem Informasi ${ }^{2}$ \\ ${ }^{1,2}$ STMIK DIAN CIPTA CENDIKIA KOTABUMI \\ Jl. Negara no.03 Candimas Kotabumi Lampung Utara Kodepos.34581 \\ E-mail : merri.parida@dcc.ac.id ${ }^{1}$, merinamerina32@gmail.com²
}

\begin{abstract}
ABSTRAK
Saat ini Sistem Informasi sangatlah penting bagi para pesaing dalam dunia pendidikan. Terlebih saat ini kita hidup di era teknologi informasi yang perkembangannya begitu cepat dibandingkan di era sebelumnya. Selain itu, teknologi informasi juga memungkinkan sebuah informasi dapat diakses dalam waktu nyata dan tanpa batas waktu.

Dalam penelitian ini penulis menggunakan metode prototype. Prototype merupakan suatu pendekatan dalam rekayasa perangkat lunak yang secara langsung mendemonstrasikan begaimana sebuah perangkat lunak atau komponen-komponen perangkat lunak akan bekerja sebelum tahapan konstruksi actual dilakukan. Alasan penulis menggunakan metode ini karena memiliki tahapan-tahapan yang tercepat dengan strategi utama mengerjakan yang mudah terlebih dahulu dan di sampaikan ke pengguna sesegera mungkin. penulis menggunakan alat pengembangan starUML dengan bahasa pemrogramannya adalah PHP.
\end{abstract}

Dengan adanya sistem informasi pengolahan data alumni ini proses penambahan data alumni, pencarian data alumni baru atau lama serta penghapusan data alumni menjadi lebih mudah.

Kata kunci : Sistem Informasi Pengolahan Data, Prototyping

\begin{abstract}
At present Information Systems are very important for competitors in the world of education. Especially now that we live in an era of information technology whose development is so fast compared to the previous era. In addition, information technology also allows information to be accessed in real time and without time limit.

In this study the authors used the prototype method. Prototype is an approach in software engineering that directly demonstrates how a software or software component will work before the actual construction phase is carried out. The reason the authors use this method is because it has the fastest stages with the main strategy of doing the easy ones first and conveying it to users as soon as possible. the author uses starUML development tools with the programming language is PHP.
\end{abstract}

With this alumni data processing information system the process of adding alumni data, finding new or old alumni data and removing alumni data is easier.

Keywords: Data Processing Information System, Prototyping

\section{PENDAHULUAN}


Saat ini Sistem Informasi sangatlah penting bagi para pesaing dalam dunia pendidikan. Terlebih saat ini kita hidup di era teknologi informasi yang perkembangannya begitu cepat dibandingkan di era sebelumnya. Selain itu, teknologi informasi juga memungkinkan sebuah informasi dapat diakses dalam waktu nyata dan tanpa batas waktu.

Berdasarkan penelitian sebalumnya dari sebuah e-journal Teknik Elektro dan Komputer (2014), ISSN 2301-8402. Perkembangan teknologi informasi di seluruh dunia telah membuat hidup manusia menjadi semakin lebih mudah. Terutama sejak diciptakannya jaringan internet, komunikasi menjadi semakin tidak terbatas.

Penerapan sistem informasi menjadi begitu penting untuk menunjang kegiatan kerja. Dengan perkembangan teknologi informasi kita dapat membangun sebuah sistem informasi yang bertujuan untuk membantu meningkatkan pekerjaan lebih mudah untuk mengakses data.

Data alumni merupakan salah satu contoh dari suatu sistem informasi yang dirancang untuk dapat membantu pekerjaan dari suatu instansi atau perusahan baik dalam mengolah data sampai memberikan data secara lengkap lewat tersedianya layanan informasi berbasis web [Ivan Arifard Watung].

Di dalam dunia pendidikan juga tak luput dari kebutuhan ilmu teknologi informasi. Teknologi informasi adalah salah satu kebutuhan yang sangatlah penting dalam sebuah dunia pendidikan, teknologi informasi juga dapat memberikan rating bagi institusi tesebut. Penerapan teknologi informasi ini sangatlah membantu bagi pihak sekolah dalam penyampaian informasi pengolahan data alumni yang lebih terstruktur.

Saat ini SMA Negeri 1 Sungkai Utara dalam proses pengolahan data alumni masih bersifat manual yaitu masih menggunakan Microsoft office. File-file pengolahan data alumni yang tersimpan dalam komputer belum cukup baik dan masih tersaji dalam betuk buku besar dan juga ijazah. Sehingga sering mengakibatkan terjadinya kehilangan data dan kesulitan dalam pencarian data alumni jika ada yang memerlukan, Sering terjadi penumpukan berkas yang mengakibatkan hilangnya data atau file, belum memiliki aplikasi khusus untuk pengolahan data alumni, yaitu masih menggunakan aplikasi Dapodik (Data Pokok Pendidikan) yang terhubung langsung oleh pusat yang hanya dapat diakses oleh pihak sekolah saja.

Dalam pembahasan judul skripsi ini, metode yang direkomendasikan dalam penyelesaian masalah latar belakang di atas yaitu metode prototype dengan menggunakan aplikasi Macromedia Dreamweafer 8 dengan harapan dapat membantu dalam proses pengolahan data alumni pada SMA Negeri 1 Sungkai Utara. Berdasarkan uraian diatas penulis mengambil judul "Sistem Informasi Pengolahan Data Alumni pada SMA Negeri 1 Sungkai Utara”.

\section{METODE PENELITIAN}

\subsection{Metode Pengembangan Sistem}

Metodologi yang digunakan dalam penelitian ini adalah prototyping. Prototyping adalah salah satu pendekatan dalam rekayasa perangkat lunak yang secara langsung mendemonstransikan bagaimana sebuah perangkat lunak atau komponen-komponen perangkat lunak akan bekerja dalam linkungannya sebelum tahapan konstruksi actual dilakukan (howard, 1997).

a. Reusable prototype: prototype yang akan ditransformasikan menjadi produk final.

b. Throwaway prototype: prototype yang akan dibuang begitu selesai menjalankan maksudnya.

c. Input/output prototype: prototype terbatas pada antar muka pengguna (user interdace).

d. Processing prototype: prototype yang meliputi perawatan file dasar dan proses-proses transaksi.

e. System prototype: prototype yang berupa model lengkap dari perangkat lunak.

Tahap-tahap dalam prototyping merupakan tahap-tahap yang tercepat. Strategi utama dalam prototyping adalah kerjaan yang mudah terlebih dahulu dan disampaikan hasil kepada pengguna sesegera mungkin. 


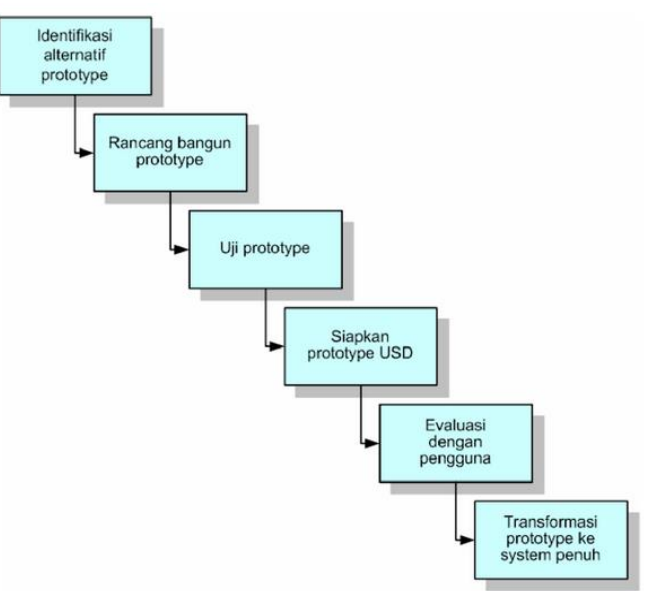

Gambar 1 Tahap-Tahap Prototyping.

Haris (2003) membagi prototyping menjadi enam tahapan, tahapan-tahapan secara ringkas dapat dijelaskan sebagai berikut:

1. Identifikasi kandidat prototyping. Kandidat dalam kasus ini meliputi user interface (menu, dialog, input dan output), file-file transaksi utama, dan fungsi-fungsi pemrosesan sederhana.

2. Rancang bangun prototype dengan bantuan software seperti word processor, spreadsheet, database, pengolah grafik, dan software CASE (Computer-

Aided System Engineering).

3. Uji prototype untuk memastikan prototype dapat dengan mudah dijalankan untuk tujuan demonstrasi.

4. Siapkan prototype USD (User's System Diagram) untuk mengidentifikasi bagian-bagian dari perangkat lunak yang diprototype-kan.

5. Evaluasi dengan pengguna untuk mengevaluasi prototype dan melakukan perubahan jika diperlukan.

6. Transformasikan prototype menjadi perangkat lunak yang beroperasi penuh dengan melakukan penghilangan kode-kode yang tidak dibutuhkan, penambahan program-program yang memang dibutuhkan dan perbaikan dan pengujian perangkat lunak secara berulang.

\subsection{Metode Pengumpulan Data}

Dalam kegiatan pengumpulan data penyusunan penulisan penelitian yang dibutuhkan, penulis menggunakan teknik penulisan pengumpulan data sebagai berikut:

\section{Wawancara}

Didalam teknik pengumpulan data wawancara ini penulis berusaha mendapatkan data dan informasi yang akurat. Dalam teknik ini penulis melakukan wawancara kepada ibu $\mathrm{Hj}$. Koriya S.Pd. M.M selaku kepala sekolah dan bapak Eko Wahyudi, S.Kom. selaku guru honor dan operator sekolah SMA Negeri 1 Sungkai Utara untuk mendapatkan data dan informasi yang penulis butuhkan

\section{Observasi/Pengamatan}

Dalam teknik pengumpulan data dengan cara melakukan pengamatan langsung dan mencatat data dan informasi yang penulis dapatkan di SMA Negeri 1 Sungkai Utara.

\section{Studi Pustaka}

Dalam teknik ini penulis melakukan pengumpulan data dengan cara mempelajari sumber kepustakaan seperti jurnal, buku-buku referensi, dan bacaan-bacaan yang ada kaitannya dengan judul penelitian, penjelasan tentang starUML serta macromedia dreamweaver 8 .

\section{HASIL DAN PEMBAHASAN}

\subsection{Hasil Program}

Tampilan hasil program dalampenelitian ini adalah sebagai berikut:

\subsubsection{Tampilan Home}

Pada gambar 2 dibawah ini kita dapat melihat tampilan home yang dapat di kunjungi oleh setiap user ketika user berhail memasukan alamat website.

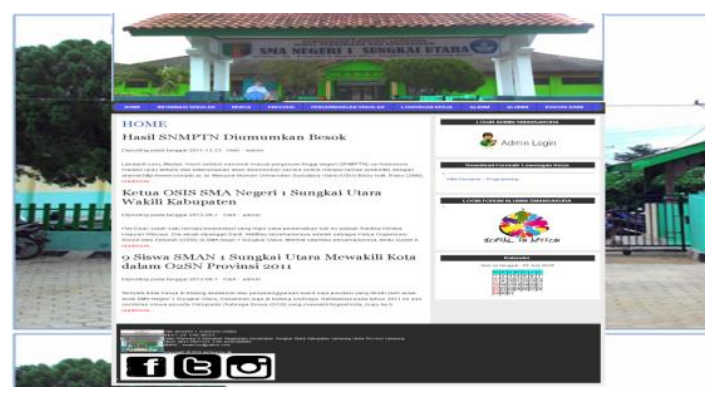


Gambar 2 Tampilan Home.

\subsubsection{Tampilan Log In Admin}

Berikut adalah tampilan halaman login untuk admin.

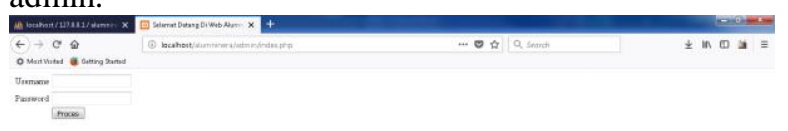

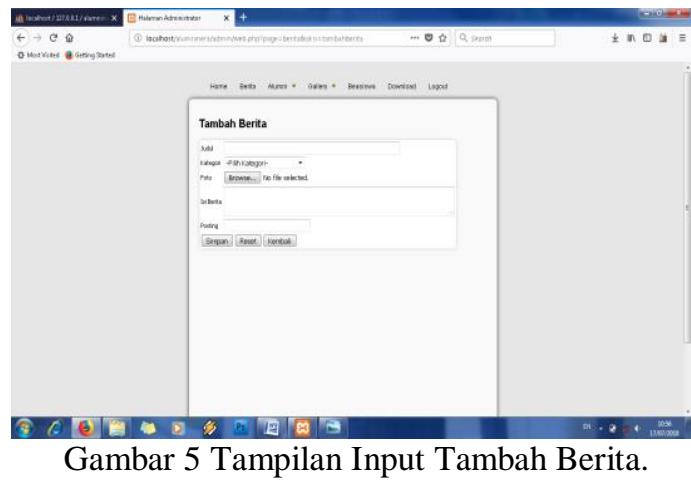

\subsubsection{Tampilan Input Tambah Galeri}

Pada halaman admin dapat melihat tampilan tambah galeri, admin juga dapat mengkelola galeri seperti menambah galeri baru atau menghapusnya. Berikut adalah tampilannya:

Gambar 3 Tampilan Log In Admin.

\subsubsection{Tampilan Room Admin}

Pada gambar 4 admin ditampilkan icon-icon untuk memanajemen data pada halaman web.

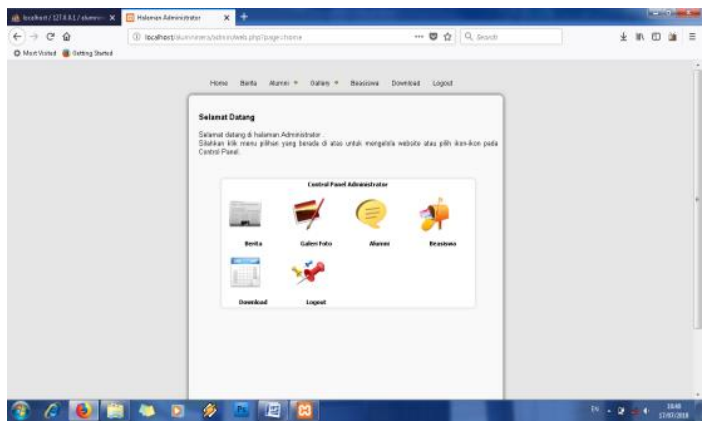

Gambar 4 Tampilan Room Admin.

\subsubsection{Tampilan Input Tambah berita}

Pada gambar 5 admin dapat mengelola berita menghapus atau menambah berita-berita baru mengenai alumni dan berita beasiswa.

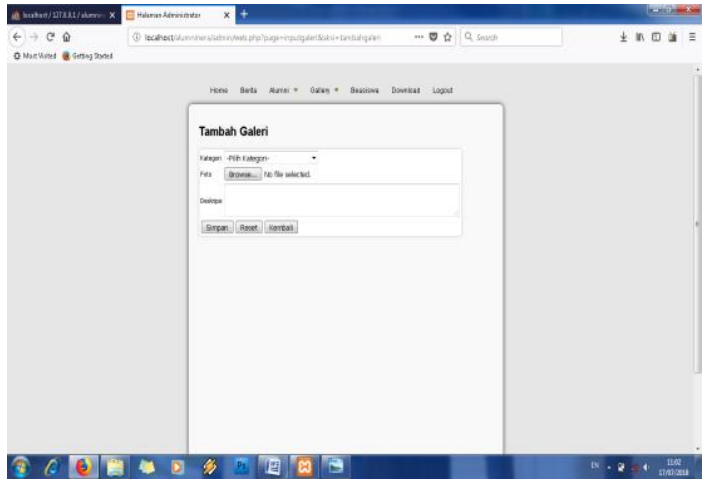

Gambar 6 Tampilan Input Tambah Galeri.

\subsubsection{Tampilan Input Kategori Galeri}

Pada gambar berikut ini adalah tampilan input kategori galeri, pada halaman ini admin dapat menghapus kategori galeri maupun menambahkan sebuah galeri baru untuk di tampilkan di halaman web tersebut. 


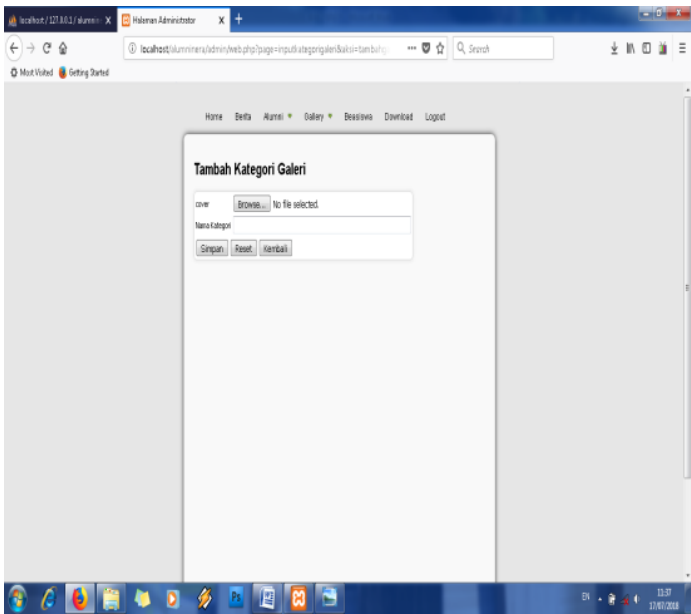

Gambar 7 Tampilan Input Kategori Galeri.

\subsubsection{Tampilan Input Tambah Alumni}

Pada gambar ini admin dapat mengkelola data admin seperti menambah data alumni atau mengubah data alumni.

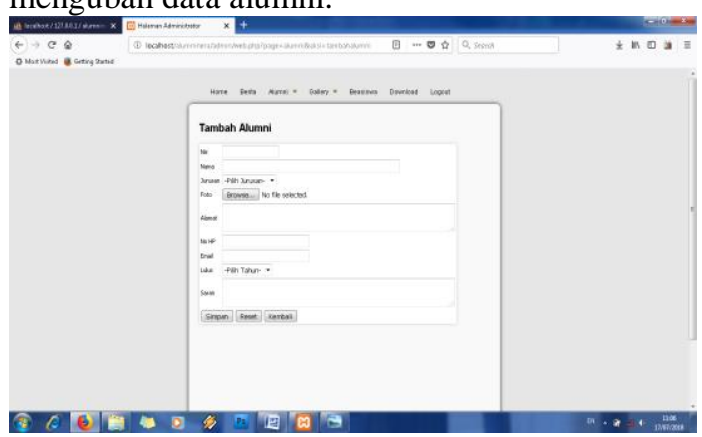

Gambar 8.Tampilan Input Tambah Alumni.

\subsubsection{Tampilan Input Kategori Jurusan}

Pada gambar berikut ini admin dapat melihat tampilan input kategori jurusan, admin juga dapat menambahkan kategori jurusan atau menghapusnya.

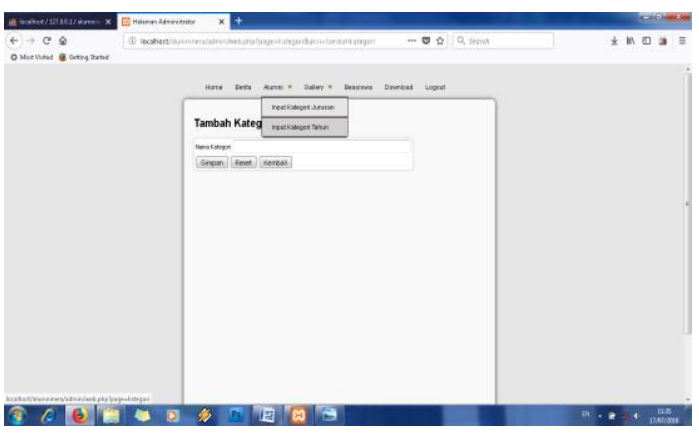

Gambar 9. Tampilan Input Kategori Jurusan.

\subsubsection{Tampilan Input Kategori Tahun}

Pada gambar ini admin dapat melihat tampilan input kategori tahun. Admin juga dapat menambahkan kategori tahun atau menghapus.

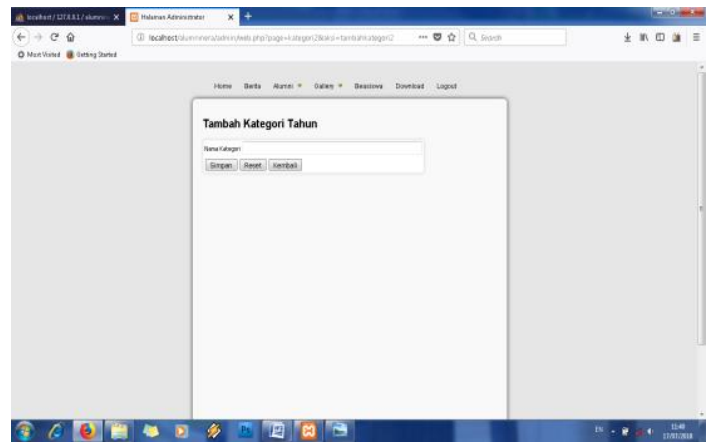

Gambar 10. Tampilan Input Kategori Tahun.

\subsubsection{Tampilan Input Beasiswa}

Pada gambar ini admin dapat melihat tampilan, menambahkan berita beasiswa atau menghapusnya.

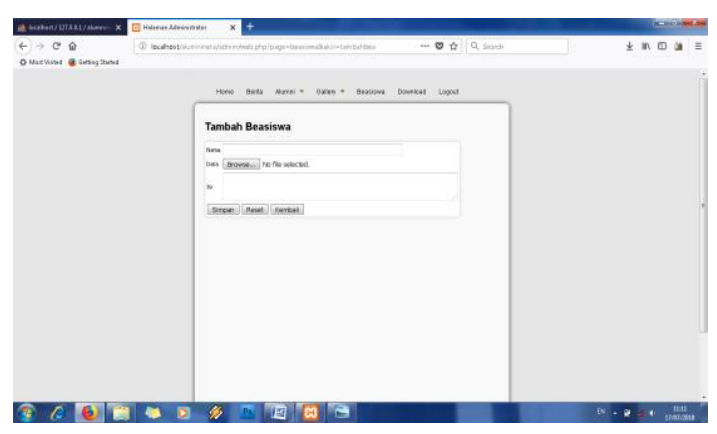

Gambar 11. Tampilan Input Beasiswa.

\subsubsection{Tampilan Tambah Download}

Pada gambar ini admin dapat melihat tampilan tambah download, menambahkan download atau menghapusnya. 


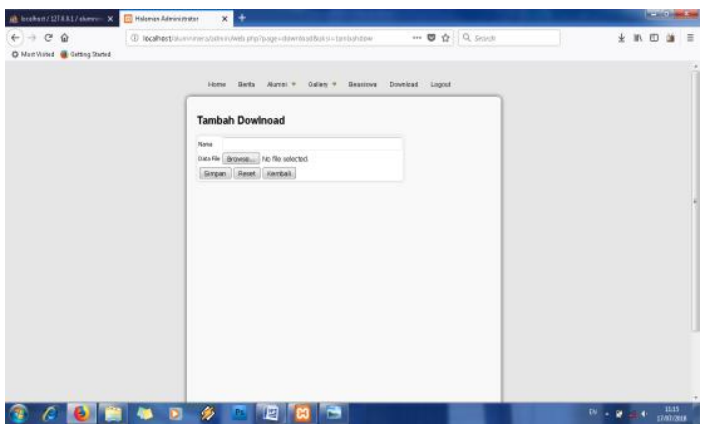

Gambar 12. Tampilan Tambah Download.

\subsubsection{Tampilan Menu Informasi Sekolah}

Pada gambar tampilan ini kita dapat melihat menu-menu pada informasi sekolah yang ada di SMA Negeri 1 Sungkai Utara.

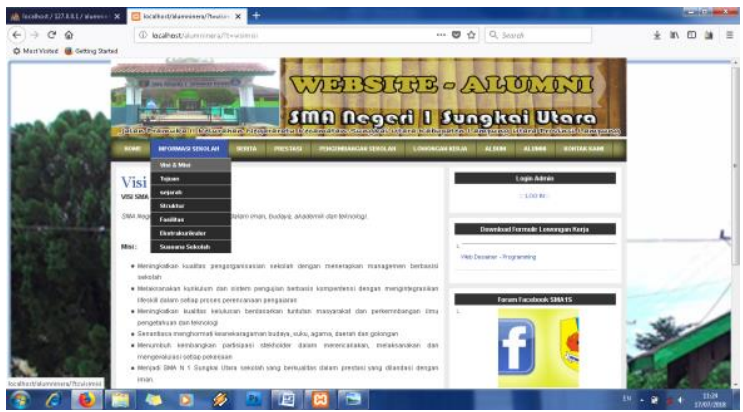

Gambar 13. Tampilan Menu Informasi Sekolah

\subsubsection{Tampilan Menu Berita}

Berikut adalah gambar tampilan pada menumenu berita. Di menu ini terdapat betita tentang kumpul alumni dan berita beasiswa.

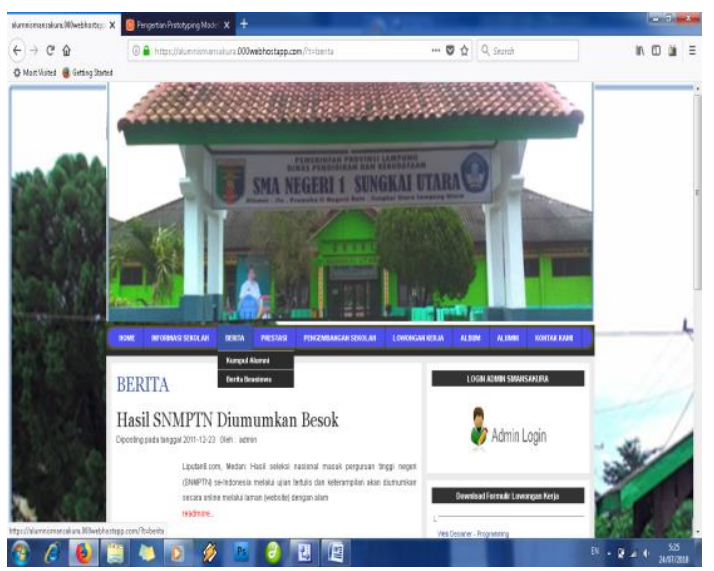

Gambar 14 Tampilan Menu Berita.

\subsubsection{Tampilan Prestasi}

berikut ini adalah tampilan pada menu prestasi. Pada menu ini kita dapat mengetahui prestasi apa saja yang sudah didapatkan oleh SMA Negeri 1 Sungkai Utara.

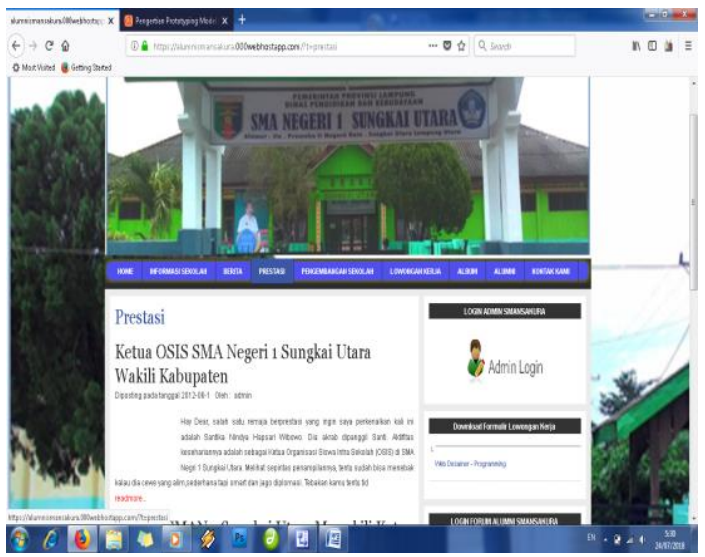

Gambar 15. Tampilan Prestasi.

\subsubsection{Tampilan Pengembangan Sekolah}

Berikut adalah tampilan pada menu pengembangan sekolah. Menu ini memberikan informasi mengenai perkembangan yang ada di SMA Negeri 1 Sungkai Utara.

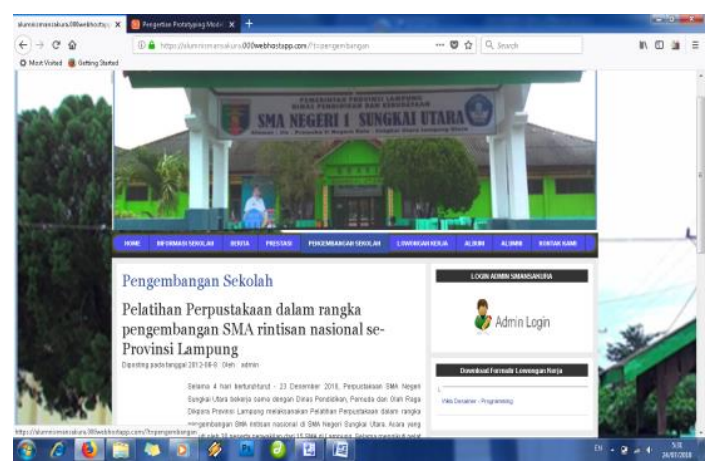

Gambar 16. Tampilan Pengembangan Sekolah.

\subsubsection{Tampilan Lowongan Kerja}

Berikut adalah tampilan lowong pekerjaan. Kita dapat melihat berita lowongan pekerjaan terbaru dan kita juga dapat mendownloadnya. 


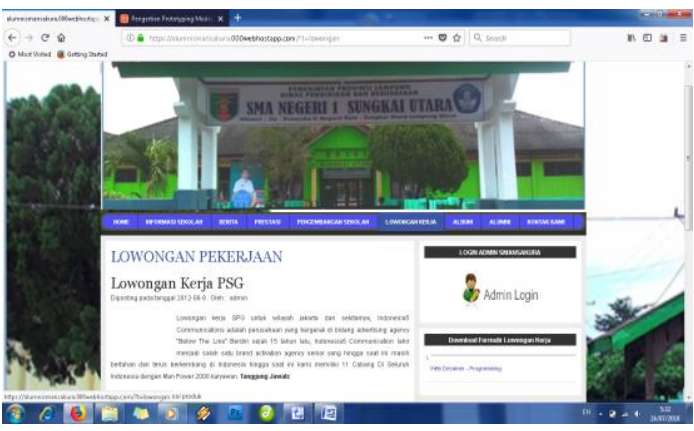

Gambar 17. Tampilan Lowongan Kerja.

\subsubsection{Tampilan Album}

Pada gambar dibawah ini kita dapat melihat sebuah tampilan dari menu album.

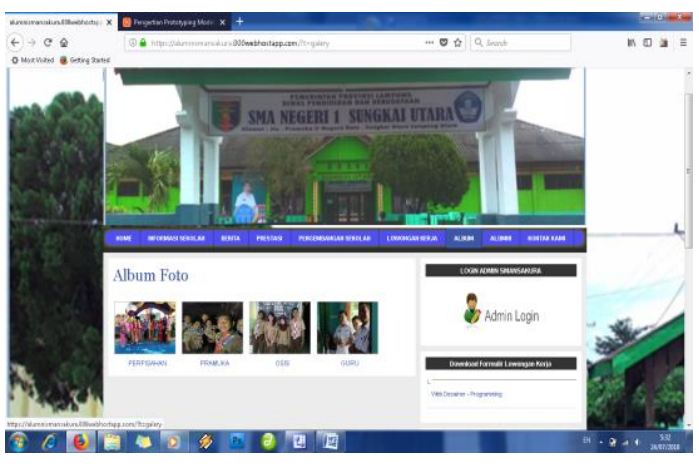

Gambar 18 Tampilan Album.

\subsubsection{Tampilan Alumni}

Gambar dibawah ini adalah gambar tampilan adata alumni SMA Negeri 1 Sungkai Utara.

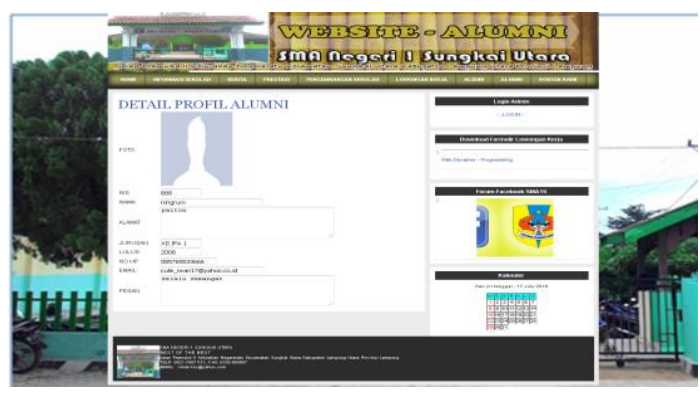

Gambar 19. Tampilan Alumni.

\subsubsection{Tampilan Kontak Kami}

Berikut ini adalah gambar tampilan kontak kami.

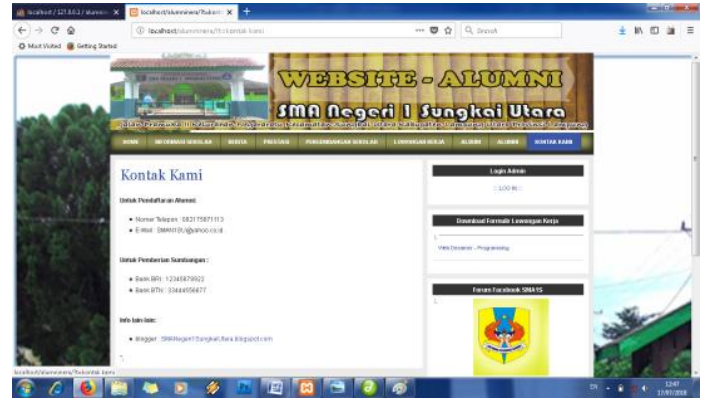

Gambar 20. Tampilan Kontak Kami.

\subsubsection{Tampilan Halaman Alumni SMA Negeri1SungkaiUtara.}

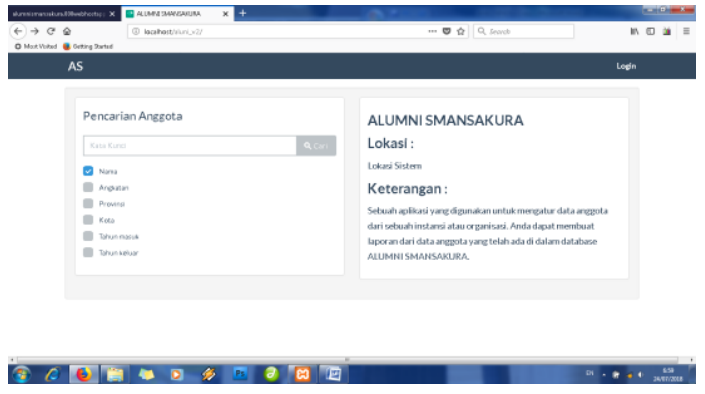

Gambar 21.Tampilan halaman alumni SMA Negeri 1 Sungkai Utara.

\subsubsection{Tampilan Login Alumni}

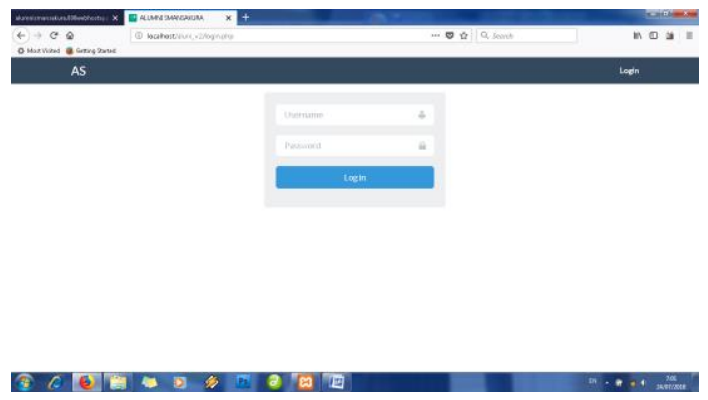

Gambar 22. Tampilan Login Alumni

\subsubsection{Tampilan Data Anggota}




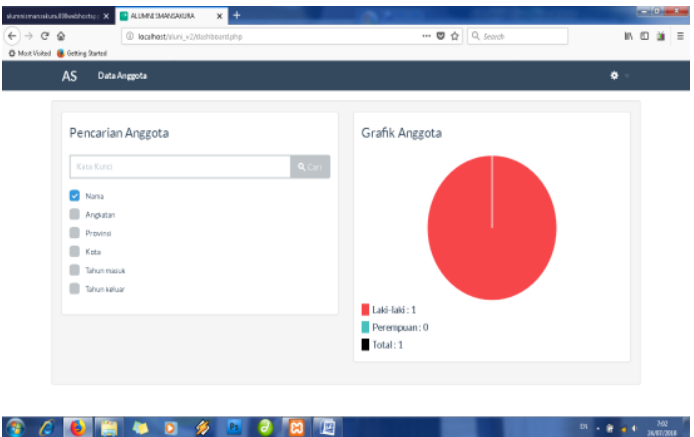

Gambar 23. Tampilan Data Anggota

\subsubsection{Tampilan Hasil Pencarian Data Anggota}

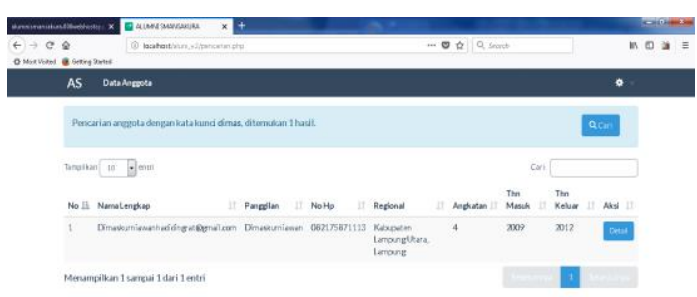

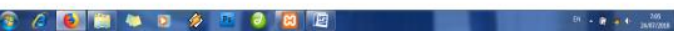

Gambar 24.Tampilan Hatil Pencarian Data Anggota

\subsection{Pembahasan Hasil Program}

Adapun tahapan - tahapan dalam pembahasan pada SMA Negeri 1 Sungkai Utara adalah sebagai berikut :

\subsubsection{Tampilan Home}

Halaman ini merupakan tampilan utama ketika user dan admin berhasil mengetikan alamat website Sistem Informasi Pengolahan Data Alumni Padasma Negeri 1 Sungkai Utara. Dalam menu home ini terdapat sub menu informasi sekolah, berita prestasi pengembangan sekolah, lowongan kerja, album, alumni dan kontak kami

\subsection{Tampilan Log In Admin}

Tampilan ini merupakan tampilan untuk masuk ke dalam sistem. Ketika admin akan, memanajemenkan sebuah data, admin terlebih dahulu harus menginputkan username dan password. Apabila terjadi kesalahan dalama penginputan username atau password maka akan muncul sebuah pesan "anda gagal login. Silahkan login kembali". Jika username dan password valid maka sistem akan menampilkan halaman selanjutnya.

\subsubsection{Tampilan Room Admin}

Halaman ini merupakan tampilan utama untuk memanajemen sebuah data ketika admin berhasil melakukan log in.

\subsubsection{Tampilan Input Tambah Berita}

Pada halaman tambah berita, admin dapat menambah berita baru dengan field-fieldnya yaitu judul, kategori, foto, isi berita, posting. Admin juga dapat mengubah isi berita, menghapus dan memposting kembali.

\subsubsection{Tampilan Input Tambah Galeri}

Pada halaman tambah galeri admin dapat menambahkan foto-foto baru dengan fieldfieldnya adalah kategori, foto, deskripsi atau menghapusnya

\subsubsection{Tampilan Input Kategori Galeri}

Pada halaman ini admin dapat menambahkan kategori galeri dengan field cover dan nama kategori. Admin juga dapat mengubah dan menghapus kategori galeri.

\subsubsection{Tampilan Input Tambah Alumni}

Pada halaman ini admin dapat menambahkan data alumni, mengubah data alumni dan mengposting kembali data alumni dengan fieldfield NIS, nama, jurusan foto, alamat, no. hp, email, lulus dan saran.

\subsubsection{Tampilan Input Kategori Jurusan}

Pada halaman ini admin dapat menambahkan kategori jurusan dengan field nama kategori. Admin juga dapat mengubah dan menghapus kategori jurusan.

\subsubsection{Tampilan Input Kategori Tahun}

Pada halaman ini admin dapat menambahkan kategori tahun dengan field nama kategori. 
Admin juga dapat mengubah dan menghapus kategori tahun..

\subsubsection{Tampilan Input Tambah Beasiswa}

Pada halaman ini admin dapat menambahkan beasiswa baru, mengubah data beasiswa, menghapus dan memposting kembali beasiswa tersebut dengan field-fieldnya yaitu nama, data dan isi.

\subsubsection{Tampilan Input Tambah Download}

Pada halaman ini admin dapat menambahkan menu download dengan field nama dan data file atau menghapusnya.

\subsubsection{Tampilan menu informasi sekolah}

Halaman ini merupakan tampilan tentang informasi-informasi sekolah dengan menu-menu yang ditampilkan yaitu visi dan misi, tujuan, sejarah, struktur, fasilitas, ekstrakulikuler dan suasana sekolah yang dapat di akses oleh setiap user.

\subsubsection{Tampilan Berita}

Pada halaman ini kita dapat melihat tampilan berita-berita terbaru mengenai kumpul alumni dan berita beasiswa. Kita juga dapat mendownload berita-beriita yang ada di halaman tersebut.

\subsubsection{Tampilan Prestasi}

Halaman ini merupakan tampilan tentang prestasi-prestasi apa saja yang pernah dicapai oleh SMA Negeri 1 Sungkai Utara.

\subsubsection{Tampilan Pengembangan Sekolah}

Halaman ini merupakan tampilan tentang pengembangan sekolah. Tampilan yang memberikan informasi perkembangan apa saja yang ada di SMA Negeri 1 Sungkai Utara.

\subsubsection{Tampilan Lowongan Kerja}

Halaman ini merupakan tampilan tentang infrmasi-informasi lowongan pekerjaan terbaru. Kita juga dapat mendownloadnya melalui download formulir lowongan kerja.

\subsubsection{Tampilan Album}

Halaman ini merupakan tampilan tari output galeri. Tampilan album ini memberikan kita informasi tentang kengiatan-kegiatan apa saja yang dilakukan di SMA negeri 1 Sungkai Utara tersebut.

\subsubsection{Tampilan Data Alumni}

Halaman ini merupakan tampilan data-data alumni. Pada tampilan ini kita dapat mengetahui informasi tentang alumni, kita juga dapat menjalin silaturahmi kepada para alumni SMA Negeri 1 Sungkai Utara.

\subsubsection{Tampilan Kontak Kami}

halaman ini menampilkan informasi kontak SMA Negeri 1 Sungkai Utara yang dapat membantu kita untuk mendapatkan informasi lain mengenai SMA Negeri 1 Sungkai Utara.

\section{PENUTUP}

\subsection{Kesimpulan}

Setelah melalukan penelitian tenyang sistem informasi pengolahan data alumni pada SMA Negeri 1 Sungkai Utara, dari hasil pembahasan yang penulis uraikan pada bab-bab di atas dapat di tarik kesimpulan diantaranya adalah sebagai berikut:

a. Dengan adanya sistem informasi pengolahan data alumni ini dapat memudahkan dalam pencarian alumni baru atau alumni lama

b. Dengan adanya sitem informasi pengolahan data alumni berbasis web ini, maka dalam perubahan data baik itu penambahan data atau penghapusan data akan lebih mudah.

c. Dengan adanya sistem informasi ini alumni mendapatkan informasi-informasi terbaru seperti data alumni, lowongan pekerjaan atau beasiswa.

\subsection{Saran}

Adapun sara-saran yang dapat penulis sampaikan adalah sebagai berikut:

a. Semoga sistem yang penulis rancang ini dapat dijadikan perbandingan antara sistem 
yang sedang berjalan dalam menangani masalah penglahan data alumni.

b. Penulis tentunya masih banyak kekurangan dalam karya ilmiah ini, diharapkan pada penelitian selanjutnya agar lebih baik lagi. Dan di kembangkan menjadi berbasis mobile phone.

\section{DAFTAR PUSTAKA}

[1] Jeperson Hutahaean, Konsep Sistem Informasi (2014), https://books.google.co.id/books $\underline{? \mathrm{id}=08 \mathrm{LjCAAAQBAJ} \& \text { printsec }}$ $=$ frontcover $\& d q=$ pengertian + inf ormasi+menurut+para+ahli\&hl= en\&sa=X\&ved=0ahUKEwigh_c 4tTaAhXJJpQKHQVTCtcQ6AE $\underline{\mathrm{LzAB} \# \mathrm{v}=\text { onepage \&q=pengertia }}$ n\%20informasi\%20menurut $\% 20$ para\%20ahli\&f=false, Tanggal Akses, 25 April 2018.

[2] Jeperson Hutahaean, Konsepsistem informasi (2014),https://books.google.co.id /books?id=o8LjCAAAQBAJ\&pg $=$ PA8\&dq=pengertian+pengolah an+data\&hl=en\&sa $=X \& v e d=0 a h$ UKEwihhtmi7tTaAhWBqZQKH ZquDBsQ6AEIQjAE\#v=onepag e\&q=pengertian\%20pengolahan $\% 20$ data\&f=false, tanggal akses 25 april 2018.

[3] Kursini, M.Kom dan Andri Koniyo, tuntutan praktis membangu sistem informasi akutansi dengan visual basic \& mocrosoft SQL server, https://books.google.co.id/books ?id=NaKZX

$\underline{\mathrm{XsJdEC} \& p g}=\mathrm{PA} 7 \& \mathrm{dq}=$ pengertia $\underline{\text { n+informasi\&hl=en\&sa }=X \& v e d}$ =0ahUKEwjdoOGX69TaAhUEi pQKHQUDCwoQ6AEIJzAA\#v= onepage\&q=pengertian\%20infor masi\&f=false, tanggal akses 25 april 2018 .

[4] Ivan Arifard Watung, Alicia A. E. Sinsuw, Perancangan Sistem Informasi Data Alumni Fakultas Teknik Unsrat Berbasis Web, 2014 https://ejournal.unsrat.ac.id/ind ex.php/informatika/article/view
13922/0, tanggal akses, 11 Mei 2018.

Indra Warman, Keni Novandri Saputra, Sistem Informasi Alumni ITP Menggunakan PHP Dan My SQL, https://ejournal.itp.ac.id/index. php/momentum/article/view/87 , tanggal akses 11 Mei 2018.

[6] Dra. Hj. Yulia Djahirn M.M. dan Dewi Pratita, S.Pd., M.Pd., bahan ajar sitem informasi manajemen

http://books.google.co.id/books ?id=RCoQCgAAQBAJ\&prints $\underline{\text { ec}=\text { frontcover } \& d q=\text { sistem }+ \text { info }}$ $\underline{\text { rmasi\&hl=en\&sa=X\&ved=0ah }}$ UKEwi7hdGs6YjbAhUIVbwK HUS-

AToQAElljAB\#v=onepage \&p =sistem\% informasi $\& \mathrm{f}=$ false, tanggal akses 16 mei 2018.

[7] Medium, pengertian use case, arifwicaksana, 1 april 2016 http://medium.com/arifwicaksa naa/pengertian-use-casea7e576e/b6bf, tanggal akses 26 mei 2018.

[8] Step by step desain proyek menggunakan UML, evi tiandini dan I gede suardika (2012) http://books.google.co.id/books ?id=3OIRBbSZq24C\&pg PA/7\&dq=Pengertian+use+ca $\&$ hl=en \&sa $=$ X\&ved $=0$ ahUKE wjcrJDk6PbAhUBWX0KHdE FDnlQ6AEIJTAB\#v=onepage $\& q=$ Pengertian $\% 20 \mathrm{use} \% 20 \mathrm{ca}$ \&f=false tanggal akses 26 mei 2018.

[9]

http://dapo.dikdasmen.kemendi kbud.go.id//70D2395B8BC8A B8E36F1 